\title{
More Than an Invalid: A Comparative Study Addressing Disability Portrayal in Children's Fiction
}

\author{
Roshini. R \\ School of Social Sciences and Languages, Vellore Institute of Technology, Chennai, India \\ Rajasekaran. V \\ School of Social Sciences and Languages, Vellore Institute of Technology, Chennai, India
}

\begin{abstract}
Children's literature or young adult literature is often seen as an elementary and casual genre, but people overlook the powerful tools it acquires in modelling attitudes and shaping children's minds. Various studies point out that society's behaviours and attitudes towards disability and people with disability are primarily based on popular culture and not personal encounters or experiences. Disability has always been an inseparable part of children's movies and stories from the beginning of times, only the magnitude to which it has been revealed has changed. This literature is seen as the most important as it introduces the world to young minds, and hence the impression it creates in children's minds would not easily be eliminated. It is also noted that young children accept differences and generate positive, acceptive attitudes during their early ages as they are less resistant and have little foreknowledge. This paper examines the disability representations in children's literature and traces the changes it has undergone as a genre from the nineteenth century to the twenty-first century. Two children's books are selected for this study, "Heidi" by Johanna Spyri and "Rules" by Cynthia Lord. The differences in the portrayal of disability and disabled characters in these novels are studied through content analysis, character study, comparison and by analyzing the linguistic symbols. This paper also ventures to decipher the norms and societal values the stereotypes were based on, and it also attempts to account for any changes.
\end{abstract}

Index Terms—disability, children's literature, stereotypical portrayal, differences, positive attitudes

\section{INTRODUCTION}

The vast corpus of Children's literature consists of novels, poems, short stories and magazines specially created for children or young adult audiences. There is a huge variety of genres that they fall into, just like adult literature with realism, fantasy, history, epics, geography, life sciences and others which are curated to suit the interests and understanding of the young audience. The concept of having a particular type of literature for children started in the seventeenth century when the widescale publishing of books for children began. Initially, books for children were meant to teach them ethics, values, morality and spiritual lessons adhering to the reformation movement that was in control of the English isles; therefore, the books were didactic, dreary and mundane. The transition from didactic children's literature to a more artistic, entertaining type of literature began with John Locke's recommendation that children should enjoy reading. This idea was taken up by John Newberry, a British publisher who started publishing books for children's gaiety, and he has been credited the title 'The Father of Children's Literature. A Little Pretty Pocketbook, which is considered as the first children's book, was one of Newberry's influential publications, along with Mother Goose's Melody and The History of Little Goody Two-Shoes (an adaptation of Cinderella). He was notable for making groundbreaking changes to the legacy of children's literature; his marketing strategies, and innovative floral prints, with games and toys in the books, helped him to get industrious profit in the publishing field and set the domain open for new children's authors and publishers like John Marshal. The Golden Age of Children's Literature began in the late nineteenth century, where a majority of the Children's Classics that are still in print were produced. It was also the time a new, exciting genre for children Picture Books was produced. The idea of the picture book was to present an aesthetic story to the children with lots of pictures and few words; Randolph Caldecott and Walter Crane were the genii behind this idea. Since then, children's literature has undergone many changes and a lot more variations to suit the tastes of the contemporary young audience who seek more than just pictures and pleasure from books. Rudine Sims (1990) came up with the idea of children's literature serving as a mirror, window and sliding door to the children who read them; the window indicates the new experiences and exposures that a child gets after reading a book, and a mirror refers to the similarities the child tries to find in itself relating herself or himself to a story character with similar attitudes, experiences, culture or race. Literature helps children to understand others, themselves and their surroundings in a better way, and they develop insights based on their experience. Thus, the assured influence of the literature that children read is quite prominent in their behavioural patterns, social lives and value structure; they can be modified, changed, 
manipulated or removed accordingly. Since our thinking pattern and ideology depend on the culture and media, we are susceptible to (Mitchell, 2002), the portrayal of disability and disabled people are of utmost importance to this study. From time immemorial, disability has been seen as a deviation from the norm, the western normate that has been fed into our cognitive system deletes and detests disability as an undesirable aberration. The disabled body was compared and contrasted with the "mutually constituting" figure of the "Normate", it is a constructed identity based on body differences and position of power (Garland-Thomson, 1997). Most of the books, movies and other media available to people in the past did not have the other since plenty of these were controlled by the dominant majority, which was white, rich, powerful and able-bodied. Until a few decades earlier, any deviation from these was seen as inferior, and thus disability never had a role to play in the media field, and consequently, with no representation, the information about the other was never entirely accurate. Instead, it was only an expression of how the normate Other saw the nonnormate other.

The children's books selected for this study are Johanna Spyri's Classic, Heidi (1881) and Cynthia Lord's Rules (2006). Both the novels are placed in different time frames and geographic locations, which would help compare the texts. The common element in both these books is that both were written for children, and most importantly, both these texts have disabled characters who are closely associated with the main character. In Heidi, there is Clara, Heidi's friend, who is a wheelchair user, and in Rules, there are two disabled characters, Catherine's brother David who has autism and Jason, who is non-verbal and also a wheelchair user, whom she befriends at her brother's occupational therapy. Since this study focuses on how the stories fed to children affect their attitudes and understanding of disability, the difference between these publications would greatly aid in mapping out the differences in society and, as a result, in people's minds over the years.

\section{REVIEW OF LITERATURE}

Biklen and Bogdan's research in 1977 reveals that all literature predominantly portrayed disabled people with a profusion of negative stereotypes, which made it simple to ignore the existence of this group of people. Their study found close associations between the portrayal of disabled people and third world countries and women who were already seen as outcasts by the people. They also inferred that these negative images reinforced oppression and created harmful metaphors presenting a distorted reality. It was also noted that the attitudes of young children usually developed through direct and indirect experiences, and thus everything that they encounter at a young age could make them feel connected to it later in life; therefore, introducing disabled people as a part of their social group can promote inclusiveness and positive attitudes. The power of children's literature is often underestimated, Pinsent in her research, observes the importance of an appropriate selection of stories for children to read. She argues that stories form the basis on which the child judges their own worth and that of others: "Literature is thus a major part of the education of children about the equality of all human beings" (Pinsent, 2007). Schwartz, in his research in 1977, applied Biklen's and Bogdan's ten stereotypes found in the media portrayals of disability to contemporary children's works and found all these negative images reinforced in a bulk of the literature that was published in the 1970s. Biklen and Bogdan identified ten stereotypes of disabled people that were very common like; "pitiable", "evil", "exotica", "object of ridicule", "super-cripple", "burden", "asexual", "their own worst enemy", "incapable of participating in everyday life" (1977). They also noted that disabled people, like women, were seen as two sides of the same coin, like how the ancient society referred to women as either a saint or a whore, disabled people were viewed as either victims or villains, as asexual or sex degenerates. As a consequence, they were always placed at two extremes as they were not allowed to take the common point in the middle, which was specially reserved for non-disabled people.

For a long time, disability was never represented in literature, and when they were, it was usually as side characters who would have nothing to do with the story or as villains or as characters who would edify the virtues of the main character, and as Rosemarie-Garland Thomson points out: '[...] they usually remain on the margins of fiction as uncomplicated figures or exotic aliens [...]' (1997). In usual fairytales and folk literature, a bodily difference or aberration from the norm was used to create fear or pity; witches, beasts, blind villains, ugly sorcerers, antagonists with a disastrous background, people punished due to their evil deeds with an impairment and the like were used as a metaphor to depict that their tainted physical characteristic is directly linked with their poor integrity or internal character traits.

According to Franks' research on fairy tales with school children, she noted that often children who were exposed to disabled characters in the stories associated them with a negative marker; she argues that messages in the human brain adhere to natural expectations that were created in their minds and reject evidence that proves otherwise (Franks, 2001). It is also observed that when canonized literature and popular texts exhibit disability, they do so in a way that they end up prescribing normativity and thus reinforce the prejudiced representation of disability, proving to be detrimental to the audience who consume it. It is also seen that the stereotyping of disability now could be the possible result of such continuous depictions.

\section{DISCUSSION}


It would not be surprising if one were to read a book published in the nineteenth century and not find any disabled characters who represent reality because it was a time when even the mere presence of a disabled character in literature was a wonder. Those were things of the past, times are changing, and now disability portrayals are not so difficult to find. We have ample texts where disabled characters share the plot, but the question is, "Is visibility enough?" (Schwartz, 1997), do they represent reality? Or do they reinforce oppression? These are some of the questions that would be answered in this study.

\section{A. Character Demographics in Heidi}

Johanna's novel of the cheerful girl of the Swiss Alps' is a children's classic that no one would have missed irrespective of their language or region. From the time of its publication, Heidi enjoyed a huge fan following and success. The characters of concern for this study are Peter's grandmother, who is blind and Heidi's friend Clara who is a wheelchair user. These images, or any disabled images for that matter, depict how they informed the society about disability and vice versa. Morality and health were seen as two variables directly proportional to each other in the nineteenth century, so it meant that if a person were hale and healthy, they would have high morals, and if one was of ill health, it implied that their moral standard was deficient. This is precisely the basis for the religious model of disability, which was very popular during the eighteenth and early nineteenth centuries. Consequently, the authors, when they started introducing disabled characters into their plot, found it very convenient to use physical or mental disability as moral and social metaphors for abnormality. Therefore, the presence of disabled characters in the novels of the nineteenth century like Johanna's Heidi is not actually inclusiveness but only a way of "demonstrating and disseminating prescriptions of normalcy."

\section{B. Reinforced Normalcy}

As discussed, most of the nineteenth-century literature used disability representations to reinforce normalcy; in Heidi, Clara Sesemann's miraculous cure at the end of the novel is the best example. Clara is introduced as a wheelchair user to the audience, but the cause of her disability is unknown. The audience is not informed if she had any medical conditions or an accident or if she was born with the disability; what is of concern is that once Clara moves to the alps with Heidi, she is cured of her disability, not with surgeries or any medical interventions, but it is a "magical cure". On the surface level, this would not seem to be of any concern, but when looked into carefully, this healing has an implied meaning, where the cure of a disability was considered a mandate for a "happily ever after" storyline. It reinstates that the life of a person with a disability cannot and will not be happy unless there is a return to the norm. The Sesemann family members are keen on Clara getting cured once she is back from the mountains and misses it. Her grandmamma says, " There is only one cure for this. If you send her back at once, she may get better in the mountain air. However, if you wait, she may not get better at all" (Spyri, 1988, p.80). Most of the texts written during the nineteenth century wrote about disability to teach the readers about moral values and ethics or to show how they would be punished if they did not live a virtuous life. So prevalently disabled characters were cured in the end to reimpose that if they adhere to the standards of normativity and change their ways, they can be cured. On the other hand, all the novels that did not offer a cure to their disabled characters insisted on showing the audience that if their virtue did not match the norm, they would not be embraced by a healing touch. So, either way, a cured disability or a non-curable disability both served an implied meaning in the novels which influenced children. As rightly stated by Seth Lerer (2009), "the history of children's literature is inseparable from the history of childhood, for the child was made through texts and tales he studied, heard and told back" (p.24).

There is another disabled character in this novel which is Peter's blind grandmother. There are many instances in the novel where Heidi and Peter's grandmother share a unique bond. Heidi's very presence makes grandmother cheerful and happy. At the beginning of the novel, Peter's grandmother is seen as a character who is murmuring and begrudging for all things; when Heidi first comes to visit her, she is seen complaining about the damaged house and about how it needs many repairs. She is never considered to be of any use by the people of Dorfli; they believed that she was "too old to understand" (Spyri, 1988, p.36). Later her personality is changed by the cheerfulness of Heidi, and she feels that there is nothing else that she needs in this world than to be where she is; she exclaims, "You have lightened my heart; dear child" (Spyri, 1988, p.88).

\section{Need for a "Magical Cure" or "Trauma-as-cure."}

Even though the field of medicine and medical innovations were on a whole spree during the late nineteenth century, Johanna chose a supernatural "cure" for a disability. This was also the time when the charity or religious models of disabilities were rejected, and the medical model appeared in mainstream literature. Not that any of them stuck to reality or helped the disabled get into the society, both were stereotypical representations of disability and sought stereotyped solutions to disability. Johanna chooses a middle ground between the religious and medical model, a standpoint that leans towards the medical model in terms of the need for a cure when one has a disability, and it also touches the religious model based on how the cure occurs. Clara is taught about God, and she trusts in the power of the spiritual and the influence of the natural landscape that helps in the cure. Heidi's grandfather also acknowledges God for Clara's cure, "God's good sun and mountain air" (Spyri, 1988, p.134). This draws parallels to Keith's (2001) 'Take Up Thy Bed and Walk: Death, Disability and Cure in Classic Fiction for Girls' where she discusses that one of the features of the 
disability portrayals of the nineteenth-century novels is that the disability can be cured if one loves themselves enough and has a positive outlook towards life. Another is that if the disabled person believes enough in God, they will be cured. Peter's grandmother, on the other hand, is not cured of her blindness in the novel. Grandmother's uncured disability is used here in the novel; to attest to the audience about the moral nature of the novel's protagonist Heidi.

As the story progresses, grandmother becomes the role model for people who are not cured but learn to deal with their disability, and she fulfils another purpose as well; she is transformed into the person who firmly believes that she needs no cure, it is said that "the children (Peter and Heidi) become her eyes in her blind and physically challenged state". Grandmother here represents the "purified" individual who views trauma as "potentially sanitizing". This concept of "trauma-as-cure" was observed by Schillace in a majority of Victorian fictions that portrayed disabled people. She noted that the existence of such disabled characters was as "moralizing agents" free from any of the moral corruptions of the world (2013). So, Peter's grandmother is used as one such agent in the text, who, because of her disability, is seen as a "paragon of Virtue".

\section{Channelling the Change in Disability Representation}

All through the late nineteenth and early twentieth century, children's books with disability awareness did not exist. The only representation of disability in the literature of that period was to show how helpless and characterless the disabled people were. The plotlines extensively placed them in a position where ill will and bad intentions were the root cause of their disability. Therefore, these novels with disabled characters were never found in the school curriculum. The complete negligence of this group of people, who were almost ten percent of the world's population, was not a coincidence but a conscious one. The powerful and able-bodied majority made conscious efforts to keep the disabled people at the margins of society, and as a result, there was no voice of their own.

As times began to change and as a result of America's ADA (Americans with Disability Act), many constitutional and administration changes started taking place all over the world in terms of treatment of disabled people, their rights and visibility in society. As a result, in 2006, the government of the UK, as an extension to Disability Discrimination act 2001, wanted schools to take responsibility to garner guidelines that would help the children to build positive attitudes towards disabilities and disabled people, they had to start by having books that encouraged a bright, inclusive attitude (Beckett, 2010). Inclusive literature was one of the fundamental ways in which children's attitudes can be changed or altered depending on what they are exposed to. Other researchers also conclude that inclusive literature can help nondisabled children to accept disabled children as 'friends'.

\section{E. Contemporary Character Demographics in Rules}

Rules by Cynthia Lord is a beautiful novel that would be a perfect addition to the corpus of disability literature. The narrator of this story is Catherine, an exuberant school kid with a younger brother who has autism. From the beginning of the novel, Catherine is not happy with her life, "You cannot pretend he does not exist" (Lord, 2006, p.37) is her mother's response when Catherine reveals her fear about David's actions. She is not proud of her brother David and always feels humiliated when she is with him, "Trouble comes quickly with David" (Lord, 2006, p.47). Catherine is an accurate representation of a non-disabled child who comes into close contact with disability. She has a varied set of rules that she gives to her brother from time to time to save herself and him from future mishaps or humiliation. Cynthia has divided the novel into various chapters, and the name of each chapter is a rule that Catherine had written for her brother. Catherine, like the true non-disablist child that she is, longs for an everyday life, "I want to yell at her, "It is not that easy" (Lord, 2006, p.50). It does not mean that Catherine hates her brother, she loves David, but at the same time, she also wants to make things better for both David and herself, which is why she makes rules for David. Once she is tired of making new rules for David, she says, "Why can't the world be simpler, like it is for guinea pigs? They only have a few rules" (Lord, 2006, p.54). She also knows that most of the time, David cannot follow her rules, but she does not stop making them until the end of the novel. David and Jason, the two crucial characters in the novel who are disabled, are closely related to Catherine. Their portrayal is quite different from a typical disabled child's depiction in a novel. Cynthia does not sugarcoat the disability experience, nor does she treat it with contempt; she finds the perfect balance between bringing out an accurate representation of the lived experience. She gives an honest portrayal of a family with a disabled child and the impact it has on the family members, especially the sibling who resents her brother's unique needs. This makes the narration credible and engaging at the same time and, in turn, helps us to understand the honest feelings of the elder sister. Jason's description or the description of the other disabled people at therapy is beautifully done without evoking negativity. Catherine describes Jason as almost grown and as someone who can move by being pushed on his wheelchair. Lord (2006) gives us a mature yet wholesome understanding of the atmosphere at therapy; none of the people there stares at others or pours out their pity. A realistic environment is portrayed, and Catherine takes utmost care not to be apathetic by staring as she knows how annoying it is when people stare at her brother. Later in the novel, Catherine feels Jason's family understands David because "... we are as different as they are..."(p.103). Jason's description of himself at therapy speaks for the whole disabled community. He feels that he could better die, a pervasive feeling since time immemorial for the disabled, not because they want to die, it is because of society's disabling attitudes and reactions that make them feel worthless. Jason, in the novel, says, "I. Am... Incomplete"(Lord, 2006, p.70). 
Catherine places both David and Jason on the same scale; she shows her personal rule collection with Jason at therapy, not because he is her great friend, but because of his disability, "but Jason's different." Initially, when Jason calls Catherine as his friend, she finds it very hard to accept because all she had longed for was to get a "cool" friend like Kristi, so Catherine is very hesitant about being friends with Jason, "My lips feel dry... even if I think of us more as clinic friends than always friends"(Lord, 2006, p.43). Catherine is already tired of having an autistic brother and has not come to terms with the same; now, when she thinks of having another disabled friend, she does not quite like the idea and brushes them off as "clinic friends", as she need not spend much time with Jason except for the days when David had his therapy.

\section{F. Destabilized Normalcy}

Cynthia is an artist when it comes to capturing sensitive things effortlessly; she debunks a pervasive widespread myth that disabled people long for a normal life or a life cured or without their disability. That is how disability had been portrayed all these years, but in reality, that is precisely the opposite of what disabled people actually feel. This is portrayed when Jason is mad at Catherine for drawing a card where she places him without a wheelchair in a park; Jason is infuriated and makes her remove it, "Want. Wheelchair. In. Picture... Take. It. Out" (Lord, 2006, p.95).

Catherine tries all she could to make David "normal" she gives him rules, looks after him, comforts him, but she could not accept the fact that he is different, she continuously tries to make him like other kids, showing her longing to be accepted by her peers, "... it is hard enough to make new friends without worrying he will do something embarrassing" (Lord, 2006, p.37). She also yearns for David to be cured, "...my always-wish, ...all his autism wiped clean"(Lord, 2006, p.82). Even though Catherine's thoughts initially prove to be disabling, there is no return to normalcy at any point in the novel. In fact, Catherine changes her mind at the end of the novel to accept both David and Jason as they are. Another important observation that Cynthia subtly exposes is the fact that disabled people have few or no friends. Catherine notices the absence of the word "friend" in Jason's communication book, and she makes him one, "I wonder why he did not have it already" (Lord, 2006, p.43). In the same way, David also does not have many friends, "He does not have any friends- not like you have." The author represents reality as it is and encourages the audience to become more inclusive by making them empathize with the characters. Jason and David both have difficulty in communicating; David cannot form his sentences but echoes them and loves dialogues from Frog and the Toad Together. Jason, on the other hand, cannot communicate verbally and uses a communication book. Catherine, contrastingly, does not always communicate what she thinks; she avoids saying certain things to appear friendly to Kristi. This reiterates the idea that all are different, with or without disability, and that all differences can be accommodated.

\section{G. Cure as a Non-necessity}

Towards the end of the novel, and the audience does not witness a cure but a more confident and independent Jason and an unchanged David but a transformed Catherine. Catherine is portrayed as an ordinary twelve-year-old girl who wants a "normal" life, "But the best part of being at a friend's house is I can be just me and put the sister part of me down" (Lord, 2006, p.54). Her emotions take a roller coaster ride when she is torn between David, Jason and Kristi, and her struggles tell the story of disability from a rarely heard perspective. Catherine's description of David can be seen as adhering to the stereotypes of the past, but it is the result of her exhaustion as a struggling twelve-year-old, "How can his outside look so normal and his inside be so broken? Like an apple, red perfect on the outside, but mushy brown at the first bite"(Lord, 2006, p.66).

The change in Catherine is visible at the end of the novel when she starts accepting David and Jason for who they are. Catherine, who had always felt embarrassed of her younger brother, takes him to the community dance happily and even fulfils his "wish" by getting his grape soda. Kristi and Ryan are the representation of the rest of the society that is insulting and hurtful towards people with disability. Kristi does it out of ignorance, but Ryan does it for entertainment; he finds hurting David fun and thus is the perfect example of whom one should not become; the perfect high school bully. He is filled with contempt and acts like a jerk with David to fit into the "cool guy" standard. Kristi's and Ryan's choice of words speak about their disabling attitudes, "Even regular little brothers are a pain"(Lord, 2006, p.51), says Kristi when she goes to Catherine's house, and Ryan humiliates David by mocking him, "It's a miracle... You're cured"(Lord, 2006,p.65).

Cynthia has given a very realistic picture of life with an autistic kid, unlike the nineteenth-century stories where a "miraculous cure" created a perfect and happy ending to the story. At the end of this story, neither David nor Jason is cured of their disability. The only "cure" or "change" that occurs in the novel is to Catherine, who finds out the true meaning of being a "normal" girl. So, Cynthia Lord subverts the "happily ever after" concept that was very common in most of the disability texts.

\section{CONCLUSION}

Why should children's literature take up so much effort to present disability in a positive light? The answer to this question would be that not just children's literature but the whole literary corpus has a massive responsibility in giving out a realistic account of disability and disabled people, not a fake optimistic outlook which would be a euphemism or a 
didactic approach that enforced normativity, but an accurate representation about disabled people. Children, irrespective of which age or era they belong to, develop and grow in the same way. Books play a vital role in helping them to decipher and understand the world they are in, because early intervention helps in establishing their basic understanding of the people, place and environment they live in, and that would act as the blueprint they would base their lives on. The portrayal of disability in Heidi and Rules is not the same, the nineteenth-century novel is, unfortunately, pessimistic even though it appears harmless superficially, and the novel of the twenty-first century is very inclusive and realistic. Usually, disabled characters were used in old novels to approve the construction of normality and thus stereotypically treat disability. Both the novels have a happy ending but are totally different from each other; the nineteenth-century version of a happy ever after meant a "normal", "non-disabled", or "cured" life. In the twentieth century, a happy ending did not mean a cure or ordinary life but a life of understanding and acceptance.

Catherine, who had earlier wished for her brother's cure, wishes for a more conducive and fairer world; "I wish everyone had the same chances." Children's books are especially important because they sow the first seeds about the world outside and lay the foundation for developing positive or negative attitudes, so a fair starting point can be an excellent solution to develop a more inclusive society. Undoubtedly there is a lot more that needs to be done, but many contemporary authors strive to make the dream of inclusivity come true. Even though it is not fast enough, we can be sure of a time in future when stereotyping would become a thing of the past and inclusive environments would adorn the world. The final lines of Catherine in Rules (Lord, 2006) are a genuine encouragement of the same. "I let that be enough" (p.115).

\section{REFERENCES}

[1] Ayala, Emiliano C. (1999). "Poor little things" and "Brave little souls": The portrayal of individuals with disabilities in children's literature". Reading Research and Instruction, 39.1(1999):103-117. https://doi.org/10.1080/19388079909558314

[2] Barnes, Colin. (1992). Disabling imagery and the media. An exploration of the principles for media representations of disabled people. Halifax, UK: British Council of Disabled People and Ryeburn Publishing.

[3] Beckett, Angharad et al. (2010). "Away with the fairies?' disability within primary-age children's literature". Disability \& Society, $25.3: 373-386$

[4] Biklen, Douglas, and Robert Bogdana. (1977). "Media portrayal of disabled people: A study of stereotypes." Inter-racial Children's Book Bulletin 8.6-7: 4-9.

[5] Blaska, Joan. (2004). "Children's literature that includes characters with disabilities or illnesses". Disability Studies Quarterly, 24.1. https://doi.org/10.18061/dsq.v24i1.866.

[6] Davis, Lennard J. (2002). "Constructing Normalcy.” Disability Studies. Ed. Sharon L. Snyder, Brenda JoBrueggemann, and Rosemarie Garland Thomson. New York: Modern Language Association of America. 3-19. Print.

[7] Franks, B. (2001). "Gutting the golden goose: Disability in Grimms' fairy tales." Embodied rhetorics: Disability in language and culture. Ed. James C. Wilson and Cynthia Lewiecki-Wilson. Carbondale, IL: Southern Illinois University Press. $244-58$. https://doi.org/10.1080/09687591003701355

[8] Gore, Clare Walker. (2014). "Noble Lives: Writing Disability and Masculinity in the Late Nineteenth Century." NineteenthCentury Contexts: An Interdisciplinary Journal 36.4: 363-375. https://doi.org/10.1080/08905495.2014.954428.

[9] Keith, Lois. (2001). Take Up Thy Bed \& Walk. New York: Routledge.

[10] Lerer, Seth. (2009). Children's Literature: A Reader's History, from Aesop to Harry Potter. Chicago: University of Chicago P.

[11] Lord, Cynthia. (2006). Rules. Scholastic Paperbacks.

[12] Mitchell, David T. (2002). "Narrative Prosthesis and the Materiality of Metaphor." Disability Studies. Ed. Sharon L. Snyder, Brenda Jo Brueggemann, and Rosemarie Garland Thomson. New York: The Modern Language Association of America. 15-30.

[13] Pinsent, Pat. (2007). Children's literature and the politics of equality. London: David Publishers. https://doi.org/10.4324/9781315067827

[14] Schillace, Brandy L. (2013). "Curing "Moral Disability": Brain Trauma and Self- Control in Victorian Science and Fiction." Cult Med Psychiatry 37.4: 587-600.

[15] Schwartz, Albert V. (1997). "Disability in children's books: Is visibility enough?” Inter-racial Books Bulletin 8, nos. 6-7: 1015.

[16] Spyri, Johanna. (1988). Heidi. Arena.

[17] Thomson, Rosemarie Garland. (1997). “Disability, Identity and Representation: An Introduction.” Extraordinary Bodies. New York: Columbia UP. 5-18.

[18] Yenika-Agbaw, Vivian. (2011). "Reading Disability in Children's Literature: Hans Christian Andersen's Tales.” Journal of Literary \& Cultural Disability Studies 5.1: 91-108. https://doi.org/10.3828/jlcds.2011.6

Roshini. $\mathbf{R}$ is a research scholar at the Vellore Institute of Technology, in Chennai, India. She has pursued her bachelors and masters in English Language and Literature from the prestigious Madras Christian College. Disability Studies is her core area for doctoral research, and she is ambitious about writing a thesis that will throw light on the less talked about aspects of disability and create social awareness about the rights of the disabled community. Her other areas of interest include Marxist feminism, culturalism and children's studies. 
Rajasekaran V. works as a Senior Assistant Professor at the Vellore Institute of Technology, Chennai. He has more than ten years of teaching experience and has been honoured with various titles. His research interests include Anthropology, English Language and Teaching and Disability studies. 